\section{THERMOELASTIC RESPONSE OF METALS AT DIFFERENT LOADING RATES}

RADEK PROCHAZKA, SYLWIA RZEPA, PAVEL KONOPIK

COMTES FHT a.s., Dobrany Czech Republic

DOI: 10.17973/MMSJ.2019_12_2019119

e-mail: rprochazka@comtesfht.cz

This paper deals with the thermoelastic response of ferrous and non-ferrous metals at different loading rates. The goal is to predict the stress-strain response based on temperature changes caused by adiabatic processes. These data are intended to be used for non-destructive full-field thermal stress analysis (TSA). The influence of strain rate on temperature was investigated in cyclically loaded dog-bone shape specimens with initial and reduced thicknesses under sinusoidal-profile loads. Testing parameters, such as the load magnitude and frequency were chosen with respect to the specimen design and the results of tensile tests. The dependence of thermoelastic properties of metals on loading rate was found at frequencies between 0.005 and $1 \mathrm{~Hz}$. Temperature changes at various loading rates are presented and discussed.

KEYWORDS

thermoelasticity, thermoelastic stress analysis (TSA), loading rate effect

\section{INTRODUCTION}

Thermoelastic stress analysis (TSA) relies on the fact that cyclic deformation of a material leads to changes in its temperature. The phenomenon takes place in the elastic region, where the material returns to its original shape after the force is removed. The analysis describes very small changes in temperature, on the order of fractions of ${ }^{\circ} \mathrm{C}$ [Boyce 1991]. In a test machine, when the specimen is loaded by uniaxial tension to the limit of proportionality (elastic region), its temperature drops. The thermoelastic effect can only be observed in the elastic region. In this case, temperature changes depend on the mean stress $\sigma_{\mathrm{m}}$ imposed by cyclic loading, as seen in aluminum-titanium alloys [Machin 1987]. A strong relation between temperature and the imposed stress was confirmed in nickel alloys [Andrew 1999]. For this application of TSA, adiabatic conditions must be met to obtain objective and comparable results. Adiabatic conditions were maintained by short intervals within which the load sum change occurs $\Delta \sigma_{\text {ii }}$ [Wong 1987], [Machin 1987]. Therefore, the change $\Delta \sigma_{\text {ii }}$ can be rewritten as the ratio of the cyclic change $\Delta T$ and the temperature in the reference unstrained state $T_{0}$ corrected by the parameter of the thermoelastic constant $\mathrm{K}_{0}$ according to (1) [Boley 1960].

$\Delta \sigma_{i i}=\frac{\Delta T / T_{0}}{K_{0}}$

The constant $K_{0}$ can be obtained for materials with defined physical properties and specific loading conditions [Wong 1987], [Pitarresi 2003]. The definition (2):

$K_{0}=\frac{\alpha}{\rho C_{p}}=\frac{(1-2 v) g}{E}$

where $\alpha$ is the coefficient of linear thermal expansion, $\rho$ is density of the material in the undeformed reference state and
$C_{p}$ is the specific heat capacity [Pitarresi 2003], [Tomlinson 2014]. Another substitution in the equation (2) can be used to calculate the sensitivity to changes in the mean value $\sigma_{\mathrm{m}}$ using the Gruneisen parameter g [Wong 1987], [Delennoy 1980]. Poisson's constant $v$ and Young's modulus $E$ are used in this relation. For further rearrangement of these relations one has to replace the constant $\mathrm{K}_{0}$ with the parameter $\mathrm{K}$. The variable $\mathrm{K}$ comprises changes in Young's modulus $\mathrm{E}$ with temperature and the mean stress $\sigma_{m}$ according to (3) [Pitarresi 2003].

$$
K=K_{0}-\frac{1}{\rho C_{p} E^{2}} \frac{\partial E}{\partial T} \sigma_{m}
$$

Therefore, it can be assumed that the cyclic change $\Delta T$ is straindependent as well as stress-dependent. In the calibration of TSA, mechanical properties of the metals, the geometry of the specimen, and the loading level and frequency are essential considerations for obtaining reliable results. Adiabatic test conditions can be maintained by applying cyclic stress with the critical load frequency, as discussed in this paper. Based on these assumptions, the geometry of the calibration specimen and the loading frequency were chosen. The mean stress $\sigma_{m}$ significantly influences the value of the parameter $\mathrm{K}(3)$. For this reason, the nominal stresses will be constant and the test specimen will be considered to be free from stress concentrators.

The geometry of the testing specimens is characterized by a parallel gauge portion, where strain and stress distribution as well as temperature changes are homogeneous throughout the measured section.

\section{EXPERIMENTAL PROCEDURE}

In the experimental part of the study, mechanical tests were performed to obtain the temperature-stress dependence. It was determined for a wide range of metal alloys with different strength characteristics and material thicknesses. One mean value of stress $\sigma_{\mathrm{m}}$, two loading frequencies and 17 specimens of ferrous and non-ferrous alloys were used to obtain the data.

\subsection{Test specimen geometry}

The selection of the geometry of a calibration specimen was based on the assumption of uniform deformation of the body and on minimum requirements for the testing equipment in terms of the applied force and testing velocities. An adequate strain rate $\dot{\varepsilon}$ had to be considered to ensure that it causes sufficient changes in the temperature of the specimen without excessive heat transfer to the environment. The dimensions of the body should be suitable for a wider range of metal components.

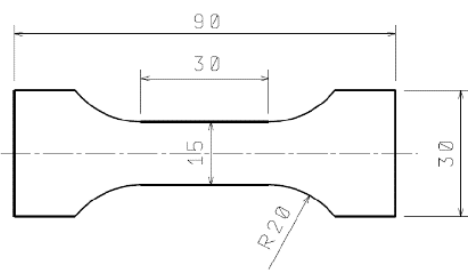

Figure 1 Specimen geometry

The parallel gauge portion of the calibration specimen, as shown in Figure 1, provides a uniform distribution of temperature and stress changes over its entire surface. Thanks to this fact, recording the temperature at certain nominal values of stress becomes much easier. The strain rate can be calculated easily using equation (4), where the loading velocity of the testing machine is divided by the length of the parallel part of the testing specimen, which is a constant value. The equation (4) allows the 
researcher to investigate the strain rate sensitivity of the tested material.

$\varepsilon^{\prime}=\frac{v}{L_{c}}$

When the strain rate changes significantly, the mechanical properties of the material change accordingly [Rund 2015], [Cadoni 2016], [Dzugan 2017]. Materials are sensitive to strain rate and work hardening can be their response to changes in strain rate. In this case, Young's modulus increases in the elastic region as does the rate of dissipation of energy and the temperature changes. It causes volume changes in the specimen tested.

\subsection{Test conditions}

\subsubsection{Loading conditions}

Flat components, such as sheets are characterized by flat crosssection with low resistance to buckling. Literature data showed that analysis of thermoelastic effect demands the cyclic loading conditions for a sufficiently long period of time, which is necessary for dissipation of energy in the tested material. For this reason, the character of loading was considered only for the cyclic tensile mode where the minimum stress is $\sigma_{\min }=0$. The described character of loading reveals a sinusoidal form, due to a smooth nature of signal, that can negatively affect the results of the test conducted at the constant load amplitude conditions $\sigma_{\mathrm{a}}=\sigma_{\mathrm{m}}$.

The loading conditions were defined on the basis of offset yield strength found by tensile testing according to EN ISO 6892-1 Tensile testing - Part 1: Method of test at room temperature. From the results, the amplitude of $\Delta \sigma$ or the peak value of maximum stress $\sigma_{\max }$, was received. The maximum stress $\sigma_{\max }$ was specified as $1 / 2$ of the offset yield strength YS. Three values of frequency were applied in the test. The results showed that adiabatic conditions were not met for the frequency of $0.005 \mathrm{~Hz}$. In the other cases, increasing the frequency from 0.1 to $1 \mathrm{~Hz}$ resulted in adiabatic conditions in the test. The change of the loading frequency required evaluation of deformation $\varepsilon_{\text {calc }}$ according to Hooke's relation (5).

$$
\varepsilon_{\text {calc }}=\frac{\sigma_{\max }}{E}
$$

Furthermore, the gripping system of the testing equipment was modified in order to obtain a uniform temperature distribution within the specimen in the unloaded state.

An illustrative sinusoidal signal of the measured temperaturestress characteristic is shown in Figure 2. Using the presented characteristics obtained at the maximum stress $\sigma_{\max }$ corresponding to half of $Y S$ of the tested material, the relative cyclic temperature change $\Delta T$ can be derived when the stress changes by $\Delta \sigma$ in the opposite direction [Harwood 1991], [Tomlinson 2004].

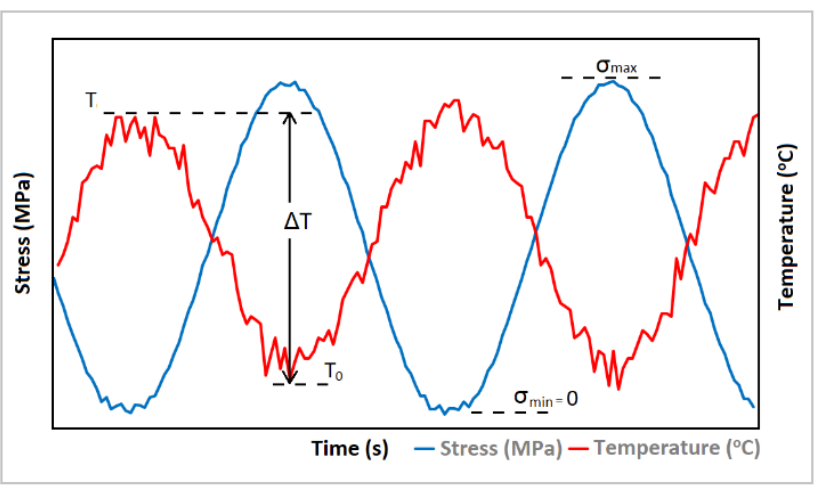

Figure 2 Schematic relationship between applied stress and resulting temperature changes

\subsubsection{IRT measurements}

The setup conditions of the thermocamera measurements have been modified no to interfere with the outcome and to achieve high repeatability and reliability of results. This concerned the measured specimen, the test machine and the test setup.

For the thermographic measurement, the sample had to be coated by application of several layers of spray with high emissivity (more than 0.9 ) to avoid metallic reflections (emissivity less than 0.2) [Usamentiaga 2014].

The properly applied paint layers allow to achieve almost zero reflection of the metal surface of the measured object. Furthermore, the applied spray layers do not affect the measurement results. In order to eliminate metallic reflections, 3 coating layers were applied, resulting in a final layer thickness of $30 \mu \mathrm{m}$. Figure $3 a$ presents one half of the specimen covered using the high emissivity spray. The same specimen is shown in Figure $3 b$ in an infrared thermographic image. Figure $3 b$ shows that metallic reflections can significantly affect the temperature record, distoring the test results.

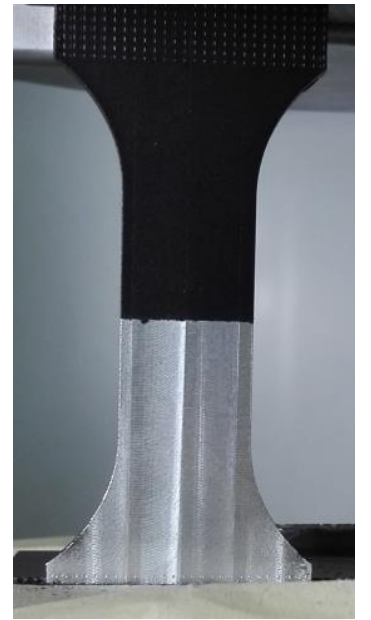

a)

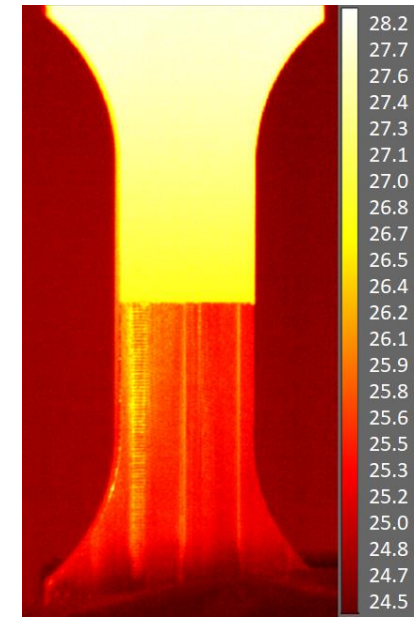

b)
Figure $\mathbf{3}$ a) The image of the test specimen captured by a optical system and $b$ ) its display in the thermogram

If ideal conditions were applied, the specimen would not interact with the environment and behave like a completely isolated system. The loading of the object in an adiabatic deformation process results in corresponding change in temperature. However, real conditions significantly vary from this ideal behaviour, and therefore changes in temperature caused by factors other than stress or deformation can be observed in the tested material. It includes mechanisms of heat transfer, mainly the convection and conduction, but the impact of plastic deformation of material on the temperature is also noticeable. A significant impact of heat transfer on the specimen temperature is typical at lower test frequencies, when gradual loading is applied and at the same time slight changes in the ambient temperature and interaction with the body occur. This factor can be reduced or eliminated by isolating the entire system, for example by placing the assembly in a chamber or a separate room with controlled testing conditions. Optimization of the temperature distribution on the surface of the measured object was performed using a steel round specimen of minimum cross-section diameter of $4 \mathrm{~mm}$ in unloaded state. 
However, if conduction affects the testing results, it might be necessary to consider a test system that isolates the test specimen from the machine grips. Figure 4 shows two cases where the temperature measurement is affected by conduction. Box 1 indicates the measured area on the sample surface and Box 2 represents the ambient temperature measured on the aluminium plate. A typical problem is excessive heating or undercooling by the clamping elements of the testing machine, see Figure 4a. The lower half of the specimen is seen to be heated due to conduction from the heated piston of the servohydraulic machine. In Figure $4 \mathrm{~b}$, the temperature in the lower half of the test sample is below ambient temperature. This is due to the use of a clamping jaw with integrated cooling. However, the described effects cannot affect the results of tests of cyclically loaded materials at higher test frequencies, but it can affect test results in the case of very slow loads under quasistatic conditions.

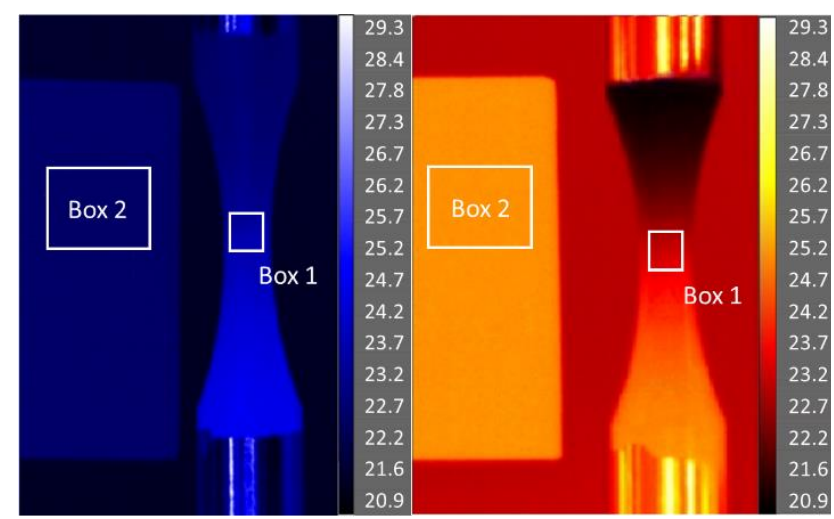

a)

b)

Figure 4 a) One side of specimen is cooles and b) heated

The thermogram of the specimen clamped in an electromechanical testing machine is shown in Figure 5. The uniform temperature distribution on the surface of the object with a temperature of approximately $24{ }^{\circ} \mathrm{C}$ is shown on the thermogram and color scale enclosed. For very low test frequencies of $\mathrm{f}_{0,005 \mathrm{~Hz}}$, the data from Box 2 was used to evaluate the temperature change $\Delta T$. For higher frequencies $f_{0.015 \mathrm{~Hz}}, f_{0.1 \mathrm{~Hz}}$ $a f_{1 H z}$, the data from Box 2 was not used.

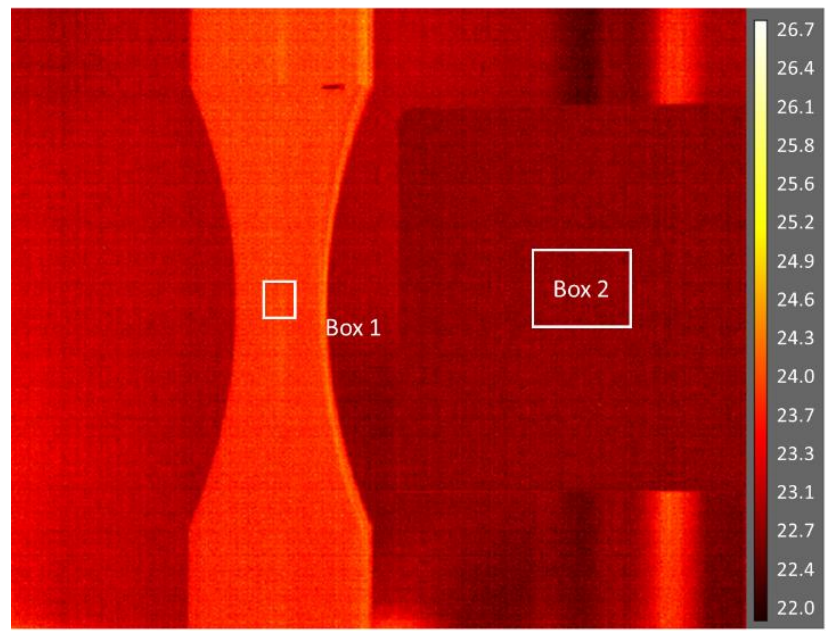

Figure 5 An optimal temperature distribution on the surface of the measured object

The correct setting of the thermographic measurement system allows the experimenter to obtain a homogeneous temperature field in the tested part of the specimens, see Figure 1. Figure 7 presents an example of the dependence of the absolute temperature change on the load change.

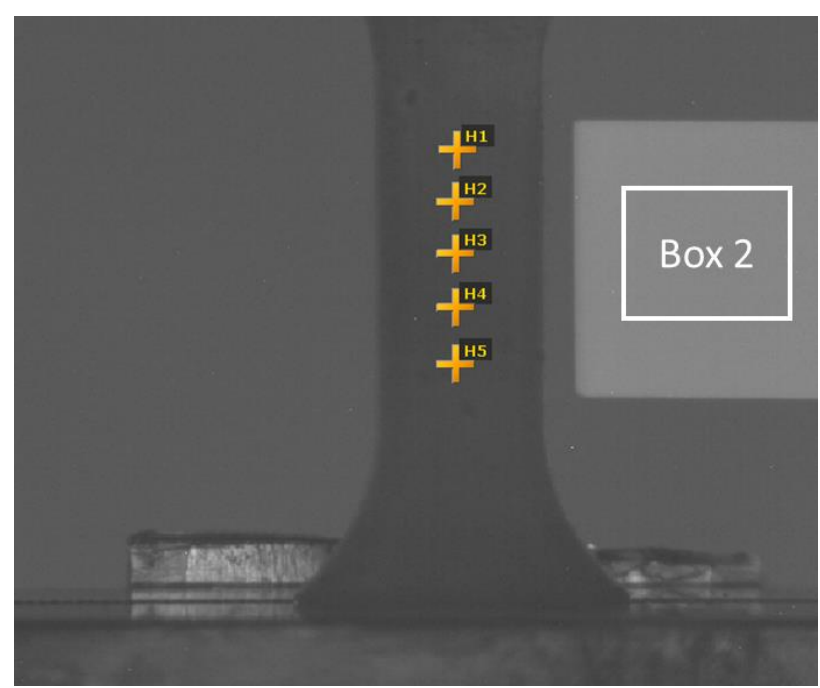

Figure 6 Temperature distribution on test specimen with marked measuring probes $\mathrm{H} 1$ to $\mathrm{H} 5$

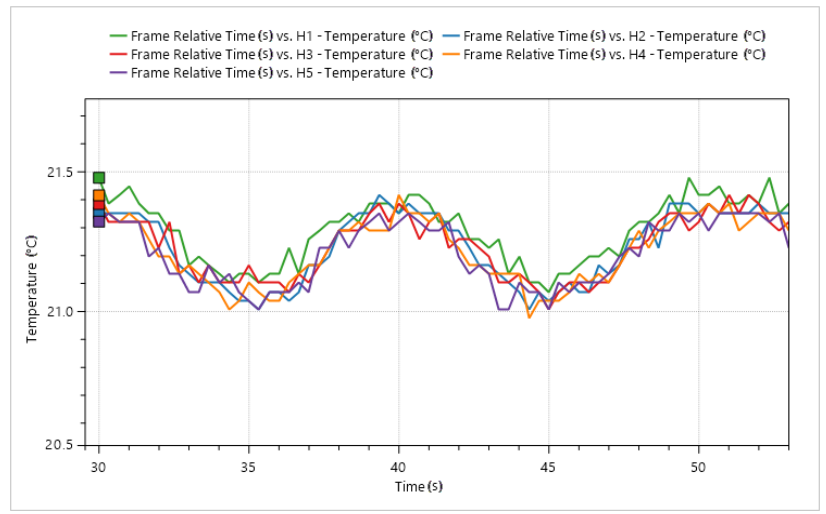

Figure 7 Absolute temperature changes measured in the active part of the test specimen during cyclic loading in elastic region 


\section{RESULTS AND DISCUSSION}

\subsection{Tensile tests}

In the experimental part of the study, 17 specimens with different thicknesses of several alloys were tested, see Table 1. The test conditions correspond to the cyclic tensile loading. The table presents the specimen sequence number, specimen thickness t, Young's modulus $E$, yield strength YS and ultimate strength UTS.

\begin{tabular}{|c|c|c|c|c|c|}
\hline Spec. & Material & t & $\begin{array}{l}\mathrm{E} \\
{[\mathrm{GPa}]}\end{array}$ & $\begin{array}{l}\text { YS } \\
{[\mathrm{MPa}]}\end{array}$ & $\begin{array}{l}\text { UTS } \\
{[\mathrm{MPa}]}\end{array}$ \\
\hline $\mathrm{Zr} \_1$ & Zr alloy & 1.03 & 91.5 & 421.8 & 481.1 \\
\hline Al_2 & AlMg3 & 1.20 & 71.7 & 114.9 & 226.9 \\
\hline Al_3 & ENAW7xxx & 3.15 & 72.0 & 327.9 & 363.6 \\
\hline St_4 & HX260 steel & 0.61 & 189.7 & 299.9 & 392.1 \\
\hline St_5 & HX180 steel & 0.67 & 203.8 & 277.4 & 385.8 \\
\hline Al_6 & AlMg3 F22 & 2.03 & 71.4 & 194.2 & 259.1 \\
\hline St_7 & Dx56D steel & 0.71 & 144.9 & 147.3 & 292.6 \\
\hline St_8 & $\begin{array}{l}\text { SPCN440W } \\
\text { steel }\end{array}$ & 1.18 & 189.4 & 340.9 & 450.0 \\
\hline St_9 & $\begin{array}{l}\text { CR500LA } \\
\text { steel }\end{array}$ & 1.81 & 218.5 & 518.7 & 628.0 \\
\hline St_10 & MoCMnSi & 0.91 & 203.2 & 923.8 & 962.7 \\
\hline St_11 & $\begin{array}{l}\text { Stainless } \\
\text { steel }\end{array}$ & 0.50 & 212.9 & 317.2 & 794.6 \\
\hline St_12 & Steel sheet & 0.95 & 189.6 & 287.4 & 539.0 \\
\hline St_13 & DC01 steel & 1.49 & 189.5 & 215.7 & 337.7 \\
\hline Al_14 & Al6005A & 9.41 & \multirow{4}{*}{61.0} & \multirow{4}{*}{240.1} & \multirow{4}{*}{260.4} \\
\hline Al_15 & Al6005A & 7.68 & & & \\
\hline Al_16 & Al6005A & 4.99 & & & \\
\hline Al_17 & Al6005A & 3.05 & & & \\
\hline
\end{tabular}

Table 1 Quasi-static tensile test results

\subsection{Specimen thickness effect}

Experimental measurements were performed only for one aluminum alloy Al6005A, Table 1, using specimens marked as Al_14, Al_15, Al_16, and Al_17. In the experiment, the temperature increment values $\Delta T$ were measured for the respective specimen thickness and frequency of the test.

The test results presented in Figure 8 did not reveal any clear trend involving changes of the specimen thickness $(3,5,8$ and 10 $\mathrm{mm})$. The results show a negligible dependence of $\Delta T$ on the material thickness $\mathrm{t}$ and a strong dependence on the test frequency. The frequencies $f_{0.005 \mathrm{~Hz}}$ and $\mathrm{f}_{0.015 \mathrm{~Hz}}$ appear to be too low to lead to adiabatic conditions. On the other hand, at the higher frequencies of $0.1 \mathrm{~Hz}$ and $1 \mathrm{~Hz}$, the values of $\Delta T$ were saturated. That indicates that these results may correspond to the adiabatic conditions correctly.

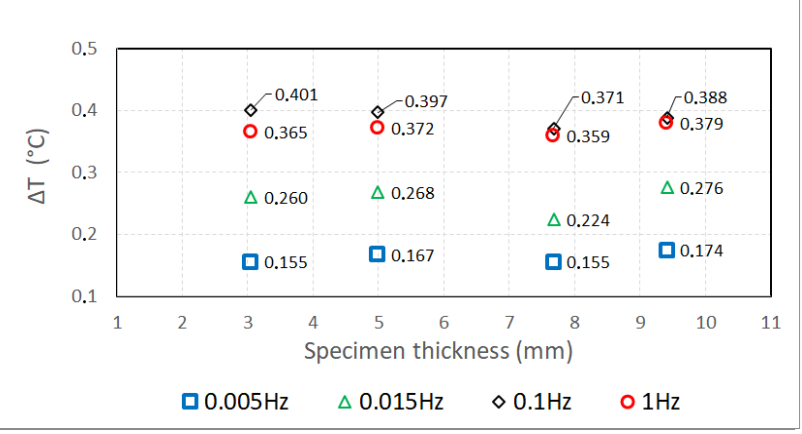

Figure 8 Effects of specimen thickness on IR measurement

\subsection{Thermoelastic response of metals at different loading rates}

Temperature-stress characteristics of the metallic materials under test are summarized in Table 2.

\begin{tabular}{|c|c|c|c|c|c|c|}
\hline \multirow{2}{*}{ Spec. } & \multirow[b]{2}{*}{$\begin{array}{l}\sigma_{\max } \\
{[\mathrm{MPa}]}\end{array}$} & \multirow[b]{2}{*}{$\begin{array}{l}\varepsilon_{\text {calc }} \\
{[\%]}\end{array}$} & $\begin{array}{l}f_{0.005 \mathrm{~Hz}} \\
{\left[\mathrm{~s}^{-1}\right]}\end{array}$ & $\begin{array}{l}f_{0.015 \mathrm{~Hz}} \\
{\left[\mathrm{~s}^{-1}\right]}\end{array}$ & $\begin{array}{l}f_{0.1 \mathrm{~Hz}} \\
{\left[\mathrm{~s}^{-1}\right]}\end{array}$ & $\begin{array}{l}f_{1 \mathrm{~Hz}} \\
{\left[\mathrm{~s}^{-1}\right]}\end{array}$ \\
\hline & & & \multicolumn{4}{|c|}{$\begin{array}{c}\Delta \mathrm{T} \\
{\left[{ }^{\circ} \mathrm{C}\right]}\end{array}$} \\
\hline$Z r_{-} 1$ & 211 & 0.231 & 0.231 & 0.203 & 0.249 & 0.292 \\
\hline Al_2 & 57 & 0.080 & 0.094 & 0.155 & 0.210 & 0.282 \\
\hline Al_3 & 164 & 0.228 & 0.202 & 0.367 & 0.559 & 0.565 \\
\hline St_4 & 150 & 0.079 & 0.198 & 0.170 & 0.152 & 0.236 \\
\hline St_5 & 139 & 0.068 & 0.147 & 0.188 & 0.173 & 0.232 \\
\hline Al_6 & 97 & 0.136 & 0.155 & 0.260 & 0.346 & 0,367 \\
\hline St_7 & 74 & 0.051 & 0.138 & 0.181 & 0.163 & 0.150 \\
\hline St_8 & 170 & 0.090 & 0.224 & 0.225 & 0.190 & 0.225 \\
\hline St_9 & 259 & 0.119 & 0.316 & 0.259 & 0.318 & 0,311 \\
\hline St_10 & 462 & 0.231 & 0.237 & 0.177 & 0.164 & 0.216 \\
\hline St_11 & 158 & 0.075 & 0.268 & 0.259 & 0.250 & 0.306 \\
\hline St_12 & 144 & 0.076 & 0.311 & 0.198 & 0.207 & 0.250 \\
\hline St_13 & 108 & 0.057 & 0.190 & 0.173 & 0.145 & 0.177 \\
\hline Al_14 & & & 0.174 & 0.276 & 0.388 & 0.379 \\
\hline Al_15 & & & 0.155 & 0.224 & 0.371 & 0.359 \\
\hline Al_16 & 120 & 0.191 & 0.167 & 0.268 & 0.397 & 0.372 \\
\hline Al_17 & & & 0.155 & 0.260 & 0.401 & 0.365 \\
\hline
\end{tabular}

Table 2 Test results at constant stress amplitude and different test frequencies

The test frequency $f_{0.005 \mathrm{~Hz}}$ (Table 2 ) is close to quasi-static test conditions. Due to long exposure of the specimen to the ambient environment, its temperature is changing. Therefore, the increment $\Delta T$ shows no dependence on the test frequency or the strain rate $\dot{\varepsilon}$. This effect can be result of the material interaction with the environment and can indicate that adiabatic test conditions have not been met.

The minimum increment of $\Delta T$ was observed in case of aluminum alloys, where heat dissipation was more intensive compared to the other tested materials. For alloy $\mathrm{Zr} \_1$ ( $\mathrm{E}=91.5$ $\mathrm{GPa}$ ) the temperature increase is almost equal to the temperature increase of steel St_11 $(\mathrm{E}=212.9 \mathrm{GPa})$, despite the fact that the deformation of the mentioned steel was 3 times lower. 


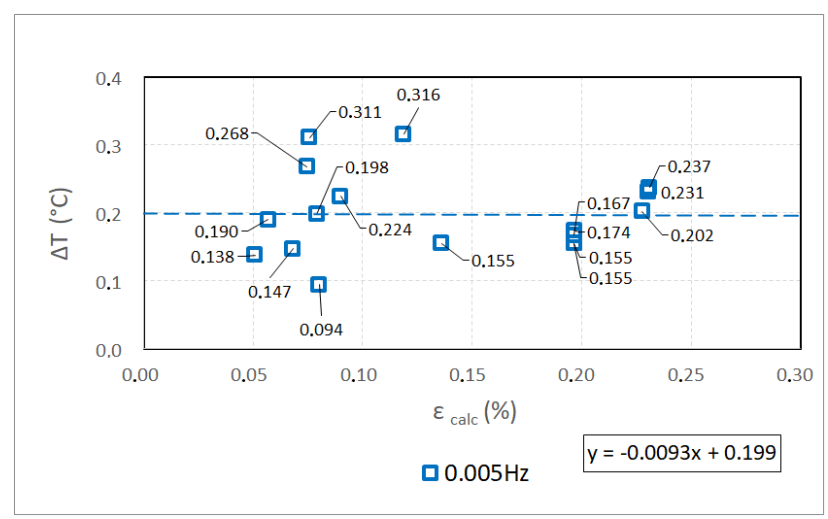

Figure 9 Temperature-strain dependence at frequency $0.005 \mathrm{~Hz}$

The results presented in Figure 10 show a slight trend of increasing $\Delta T$ with increasing calculated deformation $\varepsilon_{\text {calc. }}$. The effect of the test speed is noticeable in the case of aluminum alloys, where the time periods between the single load cycles are reduced compared to the frequency $\mathrm{f}_{0.005 \mathrm{~Hz}}$. No changes were observed in case of steel alloys.

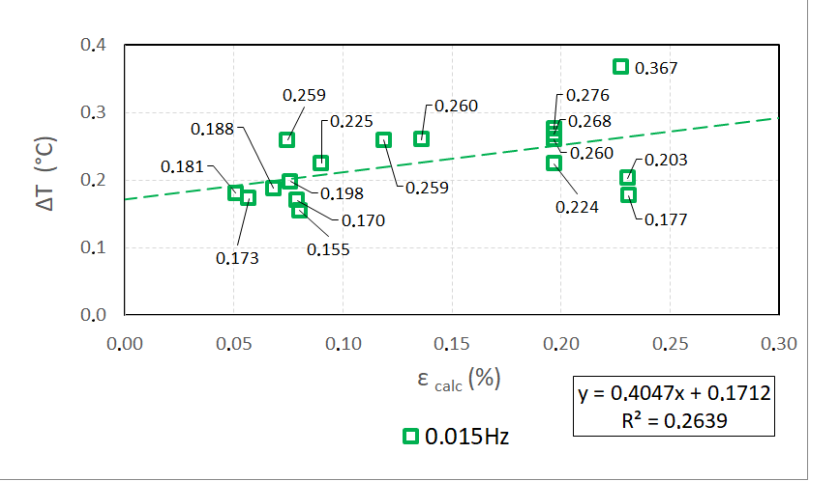

Figure 10 Temperature-strain dependence at frequency $0.015 \mathrm{~Hz}$

Increasing the test frequency to $0.1 \mathrm{~Hz}$ (Figure 11) allows to achieve the adiabatic test conditions (see Figure 8). In this case, saturation of resulting $\Delta T$ was observed. A significant increase in temperature was noticed for the alloys with lower Young modulus E such as samples Al_2, Al_3, Al_6 and Al_14 to Al_17 (see Table 1 and Table 2) with the change of the test frequency from 0.015 to $0.1 \mathrm{~Hz}$.

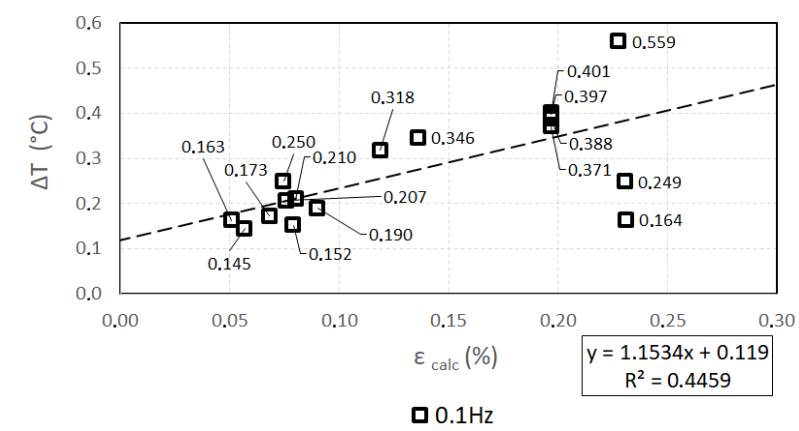

Figure 11 Temperature-strain dependance at frequency $0.1 \mathrm{~Hz}$

The greatest increase of $\Delta T$ value was observed for aluminum alloys and the lowest for steel alloys. For most of the steel alloys, such as St_7, St_8, St_9, St_10, St_12 and St_13, the increment was negligible or even negative. This effect can be caused by the measurement errors. In case of the applied frequency $f_{1 \mathrm{~Hz}}$, all the tested materials exhibit an increase of $\Delta T$, which is easy to notice when compared to the frequency of $\mathrm{f}_{0.005 \mathrm{~Hz}}$. In the case of $\mathrm{Zr} \_1$ alloy, no significant increase of $\Delta T$ was observed despite the lower $\mathrm{E}$ modulus, similar to aluminum alloys. This result corresponds to the results of steel alloys.

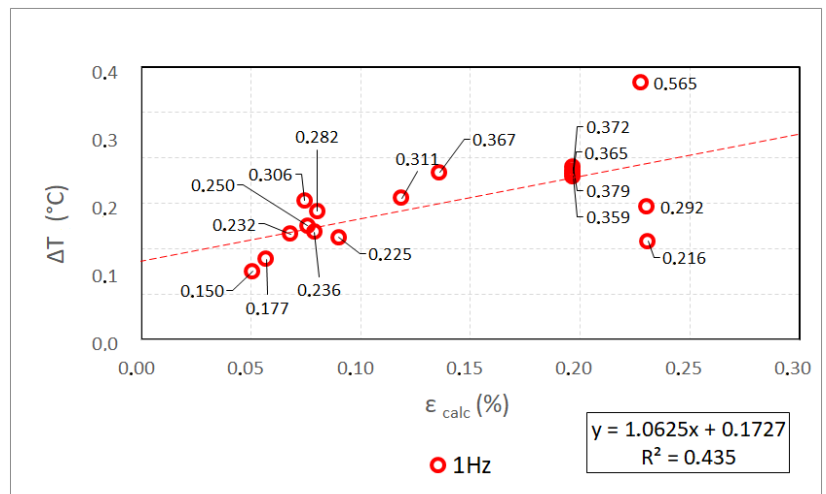

Figure 12 Temperature-strain dependence at frequency $1 \mathrm{~Hz}$

\section{CONCLUSIONS}

In this experiment, the effects of optical conditions and test setup on thermoelastic properties of metallic materials were investigated. The optical conditions included the surface treatment of the measured object performed to remove natural reflections which tend to affect the measurement results. The test setup conditions involved recommendations for clamping the specimen in the test machine and the choice of test equipment. The core of the study discussed the effects of load frequency changes on thermoelastic properties of alloys in thermoelastic stress analysis (TSA) performed on simplified objects.

The specimen thickness was not found to affect the measured thermoelastic properties. The largest temperature increments $\Delta T$ were achieved for aluminum alloys and the smallest ones for steel alloys. For this reason, the temperature-stress characteristics were measured for the selected group of materials.

It follows from the above findings that for successful calibration of TSA on specimens, it is necessary to know specific loading conditions under which the real component analysis will be performed.

The range of test frequencies confirmed saturation of $\Delta T$ between 0.1 and $1 \mathrm{~Hz}$, which can indicate adiabatic conditions. To confirm the effect of the thermoelastic response of the material on the test frequency, it would be required to increase the test frequency to $10 \mathrm{~Hz}$. Application of higher frequencies was not possible due to the capacity of the electro-mechanical machine and the test will be performed in the upcoming experiments.

\section{ACKNOWLEDGMENTS}

This paper was developed under the project Development of West-Bohemian Centre of Materials and Metallurgy No.: LO1412, financed by the Ministry of Education of the Czech Republic.

\section{REFERENCES}

[Andrew 1999] Andrew, L., et. al. Thermoelastic Stress Analysis: The Mean Stress Effect in Metallic Alloys. National Aeronautics and Space Administration, Glenn Research Center, 1999. 
[Boley 1960] Boley, B. A., et. al Theory of Thermal Stresses. New York: John Wiley and Sons Inc, 1960. ISBN 10: 0471086797

[Boyce 1991] Boyce, B. R., et. al. TSA Signal Processing and Data Collection. Thermoelastic Stress Analysis. London: Taylor \& Francis Ltd, 199, pp 71-84. ISBN10 0750300752

[Cadoni 2016] Cadoni, E., et. al. Strain rate effects on mechanical properties in tension of aluminium alloys used in armour applications. Procedia Structural Integrity. June 2016, Vol. 2,, pp 86-993. ISSN 2452-3216

[Dzugan 2017] Dzugan, J., Local Properties Determination of Titanium Turbine Blade. Acta Mechanica. August 2017, Vol. 228, No. 8, pp 2737-2739. ISSN 0001-5970

[Delennoy 1980] Delannoy, M., et. al. On the determination of the volume dependance of Gruneisen parameters in cubic and non-cubic solids. Journal of Physics and Chemistry of Solids. 1980, Vol. 41, No. 8, pp. 11-16. ISSN 0022-3697

[Machin 1987] Machin, A.S., et. al. Mean stress dependence of the thermoelastic constant. Strain. February 1987, Vol. 23, No.1, pp 27-30. ISSN 1475-1305

\section{CONTACTS:}

\section{Ing. Radek Procházka}

COMTES FHT a.s.

Průmyslová 995, Dobřany, 33441, Czech Republic

Tel.: +420 377197 358, rprochazka@comtesfht.cz
[Pitarresi 2003] Pitarresi, G., et. al. A review of the general theory of thermoelastic effect. The Journal of Strain Analysis for Engineering Design. September 2003. Vol. 38, No. 5, pp 405-417. ISSN 0309-3247

[Rund 2015] Rund, M., et. al. Investigation of sample-size influence on tensile test results at different strain rates. Procedia Engineering. 2015, Vol. 114, pp 410-415. ISSN 18777058

[Tomlinson 2004] Tomlinson, R.A., et. al. Industrial Applications of Thermoelastic Stress Analysis. Applied Mechanics and Materials. 2004, Vols. 1-2, pp 165-170. ISSN 1662-7482

[Usamentiaga 2014] Usamentiaga, R., et. al. Infrared Thermography for Temperature Measurement and NonDestructive Testing. Sensors. July 2014, Vol. 14, No. 7, pp $12305-$ 12348. ISSN 1424-8220

[Wong 1987] Wong, A. K., et. al. Thermoelastic Constant or Thermoelastic Parameter ?. Journal of Physics and Chemistry of Solids. 1987, Vol. 48, No. 8, pp. 749-753. ISSN: 0022-3697 